\title{
Decomposing Terms of Trade Fluctuations in Ethiopia
}

\author{
Josef L. Loening* \\ World Bank
}

\author{
Masato Higashi \\ Columbia University
}

August 2010

\begin{abstract}
This paper proposes a technique to decompose short-run fluctuations in the terms of trade. Using Ethiopia as an example, we decompose the commodity terms of trade into various components to measure the impact of price and volume shifts as well as export diversification. We use monthly data from the past decade, including periods during the global food and financial crises. Our findings suggest that diversification out of traditional coffee exports to other export commodities successfully mitigated a terms of trade shock. Continued export diversification will be beneficial.
\end{abstract}

Keywords: Terms of Trade, Food Price Crisis, Financial Crisis, Ethiopia.

JEL classification: F14, O11, O55.

* Corresponding author's address: World Bank, 1818 H Street NW, Washington DC 20433, USA; Email: jloening@worldbank,org.

\section{Introduction}

Developing countries were heavily affected by the food price crisis of 2007-2008.

And when global and domestic food prices started to decline, the financial crisis of 2008-2009 once again hit developing economies in several ways, in particular by slowing the demand for export commodities, resulting in the biggest decline in world trade of the past 60 years.

The aim of this paper is to assess the impact of these two global shocks on the terms of trade. Few studies have examined this topic; after the food and financial crises, we know little about how price and volume fluctuations affected terms of trade in developing countries, especially sub-Saharan Africa. Using a novel monthly data set for Ethiopia during the past decade, we decompose the country's terms of trade to study the short-run impact of the two global shocks on external trade. Ethiopia is an interesting case study — it allows us to focus solely on how the crises affected trade because there were few effects on the financial sector. At the same time, it is a relevant case because inflation of domestic food prices reached an historical record of 
92 percent in July 2008, followed by significant pressures on the balance of payments (Loening, Durevall, and Ayalew, 2009).

The remainder of the paper is structured as follows: Section 2 gives an overview of Ethiopian trade patterns, Section 3 discusses the methodology of our terms of trade decomposition, Section 4 presents the empirical results, and Section 5 concludes.

\section{Trade in Ethiopia}

During 2009, Ethiopia’s total export volume was about US\$1,600 million, while the total import volume was US\$ 7,600 million, thus producing a trade deficit of US\$ 6,000 million, equivalent to about 23 percent of GDP.

Arabica coffee not only originated in Ethiopia, but is also the country's largest export commodity. Nevertheless, as shown in Figure 1, the coffee share of exports decreased from 54 to 36 percent between 2000 and 2008. ${ }^{1}$ At the same time, the share of oil seeds, pulses, and flowers substantially increased. Ethiopia's export structure has thus diversified. On the import side, the petroleum share increased from 20 to 25 percent, food imports also increased, but machinery and vehicles imports decreased from 25 to 20 percent.

We generally find that at low levels of disaggregation — sufficient for the purpose of this paper — Ethiopian Customs Authority Data, information provided by the International Monetary Fund's Direction of Trade Statistics (DOTS), and the United Nation’s Commodity Trade Statistics (COMTRADE) database are consistent. We adopt Ethiopian Customs Authority data as well as price information from the Central Statistical Agency and exchange rate data from the National Bank of Ethiopia for the following terms of trade decomposition.

\footnotetext{
${ }^{1}$ The export volume of coffee stayed roughly the same whilst other commodities, such as pulses, rose.
} 
Figure 1. Ethiopia: Export and Import Share by Goods, 2000 and 2008
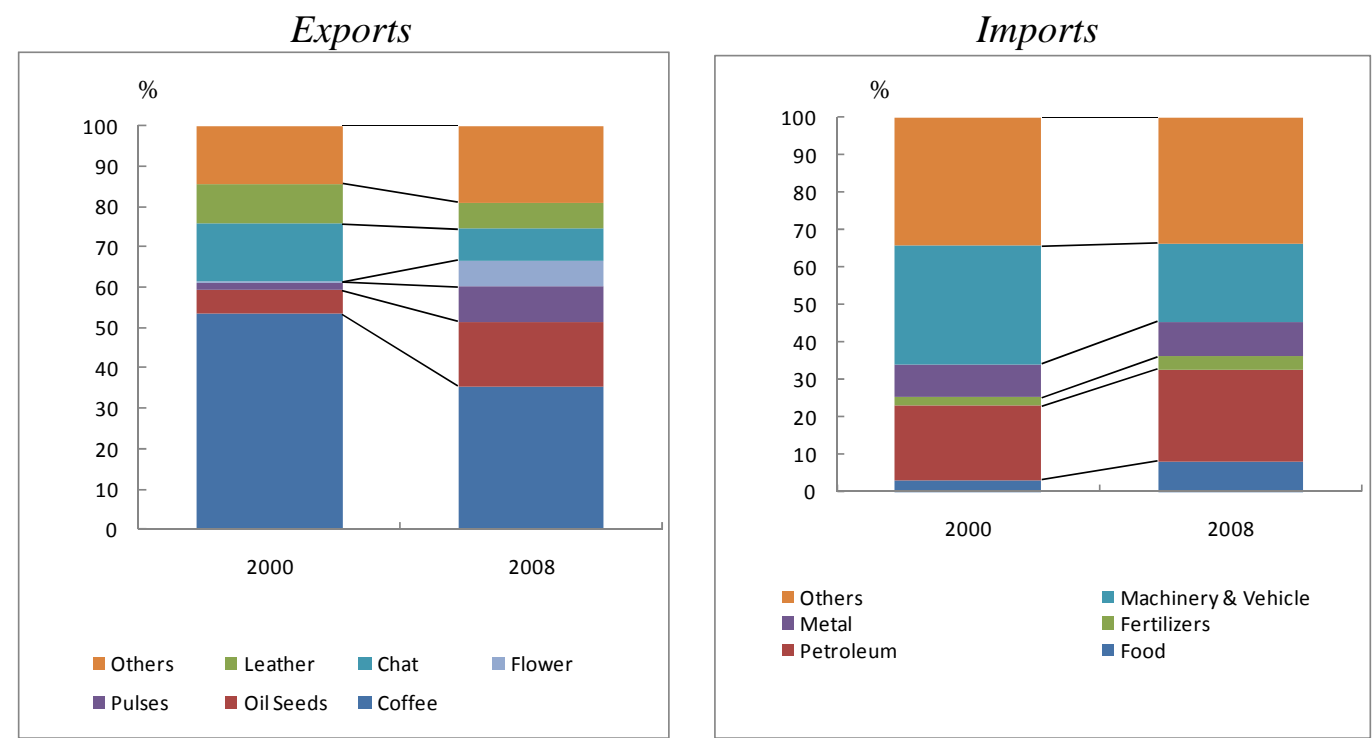

Source: Ethiopian Customs Authority and COMTRADE.

\section{Terms of Trade Decomposition: Methodology}

The commodity terms of trade measures the number of units of imports that can be exchanged for a unit of exports. Terms of trade are thought to be among the key determinants of a country's macroeconomic performance, but are often volatile and a traditional source of concern for policy-makers in developing countries (Cashin, McDermott, and Pattillo, 2004; Blattman, Hwang, and Williamson, 2007). Despite the importance of understanding terms of trade changes, there are few studies that apply decomposition analysis to analyze the approximate causes of their fluctuations.

One notable exception is Baxter and Kouparitas (2006), who decompose commodity terms of trade volatility for a panel of countries. ${ }^{2}$ They divide the terms of trade into a goods price effect, measuring differences in the composition of import and export baskets, and a country price effect, measuring the relative prices of exports and imports. A country tends to obtain a gain (or loss) in the terms of trade if it is more (or less) relatively specialized in goods whose prices are growing faster (or

\footnotetext{
${ }^{2}$ Another, more data-intensive approach to analyze income terms of trade, using a two-step variance decomposition technique, was proposed by Lloyd and Procter (1983).
} 
slower). The goods price effect measures the size of this effect. A country tends to obtain a gain (or loss) in the terms of trade if it has the ability to import at low cost in intra-sector international trade. The country price effect measures the size of this effect. Following this approach, Cardoso and Soares Esteves (2008) divide Portuguese commodity terms of trade movements into inter-sector specialization and intra-sector segmentation effects, in the same sense as the former goods and country price effects.

Developed countries export and import similar goods, thus the intra-sector segmentation (or country price) effect is a useful result. However, in our view, a limitation of this approach is that developing countries typically export and import different goods. In addition, both papers use ready-made, officially published export and import price index data, which is often not available. For an analysis of a developing country such as Ethiopia, we need to decompose the terms of trade differently. As shown in Section 2, relative specialization does not matter because of absolute specialization in coffee and a few other agricultural goods. Trading mainly commodities, it is important to evaluate the effect of changes on commodity prices and export diversification.

To illustrate the issues involved a terms of trade decomposition, we show a simplified situation in which there are only two goods in each export and import category. The commodity terms of trade $\left(T T_{t}\right)$ are:

$$
T T_{t}=P_{x, t} / P_{m, t}
$$

where $P_{x, t}$ represents the export price index, and $P_{m, t}$ represents the import price index at time $t . T T_{t}, P_{x, t}$, and $P_{m, t}$ are indices. This definition is also called net barter terms of trade or simple terms of trade index (Jemma and Zieschang, 2004). In this paper, we define the terms of trade for convenience of the following decomposition as: 


$$
T T_{t} \approx P_{x, t}-P_{m, t}
$$

This terms of trade index shows the difference of accumulated growth rates between the export price and the import price. For small values, both terms of trade indices are similar. However, when the export and import prices show a very large gap from the base level or a gap between each other, there will be a small difference between the indices. Throughout this paper, this difference should be recognized.

Next, we calculate export and import price indices. We use the export unit value index as the export price index. The export unit value index of the component $i$ is:

$$
p^{*}{ }_{x i, t}=\frac{p_{x i, t} q_{x i, t}}{q_{x i, t}}
$$

where $P_{x i, t}$ and $q_{x i, t}$ represent the export unit value and the quantity of the component $i$ at $t$. The overall export price index $\left(P_{x, t}\right)$ is a weighted average of all components:

$$
P_{x, t}=\sum_{i=1}^{n} w_{x i, t} p^{*}{ }_{x i, t}, w_{x i, t}=\frac{p_{x i, t} q_{x i, t}}{\sum_{i=1}^{n} p_{x i, t} q_{x i, t}}
$$

Similarly, for the import side, the terms of trade $\left(T T_{t}\right)$ are expressed as:

$$
\begin{aligned}
T T_{t} & =P_{x, t}-P_{m, t} \\
& =\sum_{i=1}^{n} w_{x i, t} p^{*}{ }_{x i, t}-\sum_{i=1}^{n} w_{m i, t} p^{*}{ }_{m i, t}
\end{aligned}
$$

where $w_{i, t}$ represents the export/import value weight of the $i$ component at $t$. When decomposing the terms of trade into an export and import component the equation becomes: 


$$
\begin{aligned}
& T T_{t}=P_{x, t}-P_{m, t} \\
& =\sum_{i=1}^{n} w_{x i, t}\left(p^{*}{ }_{x i, t}-p^{*}{ }_{x i, b a s e}\right)-\sum_{i=1}^{n} w_{m i, t}\left(p^{*}{ }_{m i, t}-p^{*}{ }_{m i, b a s e}\right) \\
& =\underbrace{w_{x 1, t}\left(p^{*}{ }_{x 1, t}-p^{*}{ }_{x 1, \text { base }}\right)}_{\text {Export Goods1 Efffect }}+\underbrace{w_{x 2, t}\left(p^{*}{ }_{x 2, t}-p^{*}{ }_{x 2, \text { base }}\right)}_{\text {Export Goods 2 Efffect }}-\underbrace{w_{m 1, t}\left(p^{*}{ }_{m 1, t}-p^{*}{ }_{x 1, \text { base }}\right)}_{\text {Im port Goods1 Efffect }}-\underbrace{w_{m 2, t}\left(p^{*}{ }_{m 2, t}-p^{*}{ }_{x 1, \text { base }}\right)}_{\text {Im port Goods 2 Efffect }}
\end{aligned}
$$

We next divide the terms of trade into a price change effect and a share weight change effect of the main export and import goods. If the prices of export commodities rise or the prices of import commodities fall, the terms of trade improve — and vice versa. The price change effect measures the size of this effect. In addition, changing the export and import goods basket has an impact, measured by the share weight changes effect. When decomposing the terms of trade into these two effects, the expression becomes:

$$
\left.\begin{array}{rl}
T T_{t}= & P_{x, t}-P_{m, t} \\
= & \sum_{i=1}^{n} p^{*}{ }_{x i, t} w_{x i, t}-\sum_{i=1}^{n} p^{*}{ }_{m i, t} w_{m i, t} \\
= & \left(p_{x 1, t}-p_{x 1, \text { base }}\right) * w_{x 1, \text { base }}+\left(p_{x 2, t}-p_{x 2, \text { base }}\right) * w_{x 2, \text { base }} \\
& -\left(p_{m 1, t}-p_{m 1, \text { base }}\right) * w_{m 1, \text { base }}-\left(p_{m 2, t}-p_{m 2, \text { base }}\right) * w_{m 2, \text { base }} \\
& +\left(p_{x 1, t}-p_{x 1, \text { base }}\right) *\left(w_{x 1, t}-w_{x 1, \text { base }}\right)+\left(p_{x 2, t}-p_{x 2, \text { base }}\right) *\left(w_{x 2, t}-w_{x 2, \text { base }}\right) \\
& -\left(p_{m 1, t}-p_{m 1, \text { base }}\right) *\left(w_{m 1, t}-w_{m 1, \text { base }}\right)-\left(p_{m 2, t}-p_{m 2, \text { base }}\right) *\left(w_{m 2, t}-w_{m 2, \text { base }}\right)
\end{array}\right\} \text { Price change effect }
$$

where $p_{i, \text { base }}$ represents the export and import unit value index of the component $i$ at July $2005\left(p_{i, \text { base }}=100\right)$. The first half of the equation shows the price change effect, which is expressed as the accumulated change of price multiplied by the share. The latter half of the equation shows the share weight change effect, which is written as the accumulated change of the price, multiplied by the accumulated change of share. 


\section{Decomposing Ethiopia's Terms of Trade: Results}

An overview of the movement of Ethiopia’s terms of trade is given in Figure 2. From 1999 to 2003, Ethiopia's terms of trade showed a downward trend. During the food crisis and the financial crisis, Ethiopia's terms of trade index showed some volatility, but appears stable without a visible significant shock. Since mid-2008 the terms of trade increased. Figure 2 also shows 95 percent confidence bands, suggesting that small changes should be interpreted with caution.

Figure 2. Ethiopia: Terms of Trade, 1999:7-2010:3

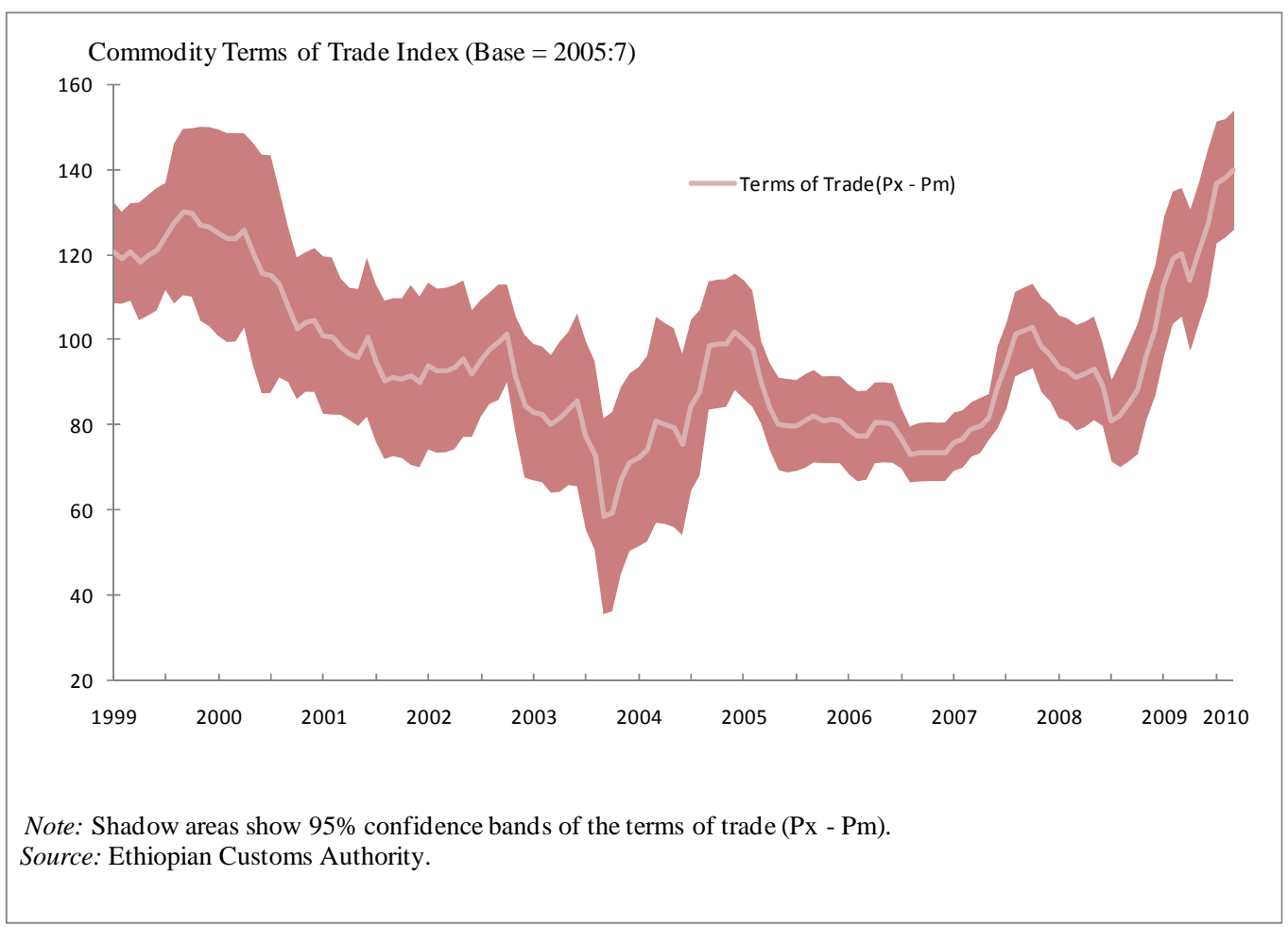


Figure 3 shows a decomposition of the terms of trade by goods. ${ }^{3}$ This decomposition is based on Equation (6). Coffee and other agricultural commodities mainly influence the movement of export prices. The key imports are petroleum products, manufactured metal goods, and grains. These items mainly determine the movement of import prices.

Figure 4 analyzes the situation in more detail. The decomposition is based on Equation (7). From 1999 to 2002, export prices dropped because of a decrease in coffee prices. During this period, the world market price fell because the world coffee supply increased rapidly, but on the other hand, prices of imported goods, including petroleum products, increased. Altogether, these factors caused a decrease in the terms of trade. High prices for key import contributions worsened the terms of trade from 2002 to 2004. The effects include grain imports (summarized in “others”).

From 2005 to July 2008, the export price of coffee and other key commodities (defined as oil seeds, flowers, and pulses), as well as the import price of petroleum products, increased. But the effects of coffee, key export commodities and petroleum products cancel each other out, and the terms of trade remained relatively stable. Similarly, since mid-2008, the export price of coffee and key commodities was stable and the import price of petroleum dropped. By contrast, the price of key imports rose, thus, their effects are cancelling each other out.

\footnotetext{
${ }^{3}$ In the decompositions we prefer to use a terms of trade series omitting the Machinery and Transportation Equipment Unit Value Index because data on quality changes of manufactured goods are limited. Nevertheless, if we choose to include this index and make assumptions about quality changes (such as fluctuations within \pm 15 percent) our quantitative overall results would only be affected marginally.
} 
Figure 3. Ethiopia: Terms of Trade Decomposition by Commodity Goods, 1999:7-2010:3

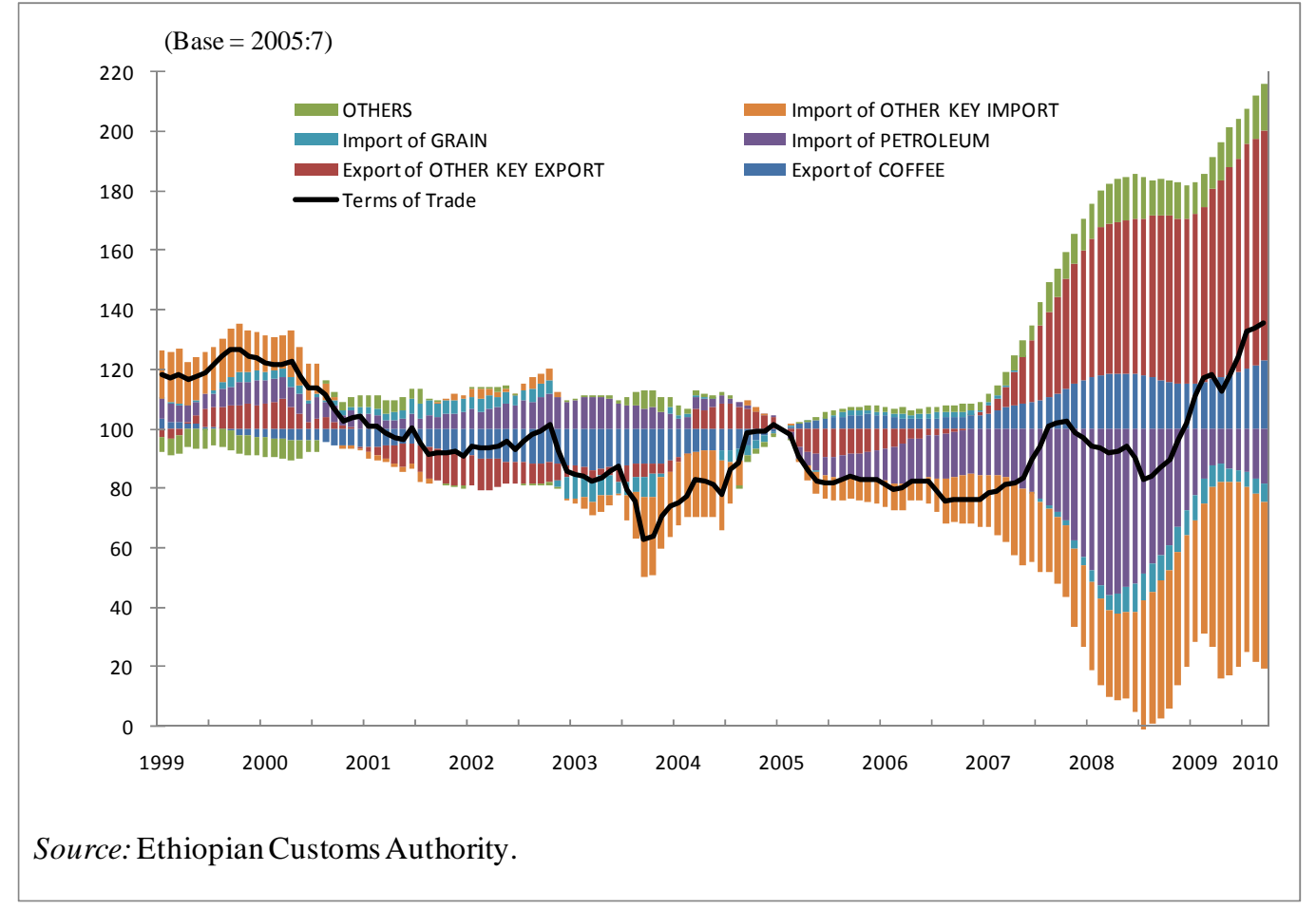

Figure 4. Ethiopia: Terms of Trade Decomposition by Price and Share Weight Change, 1999:7-2010:3

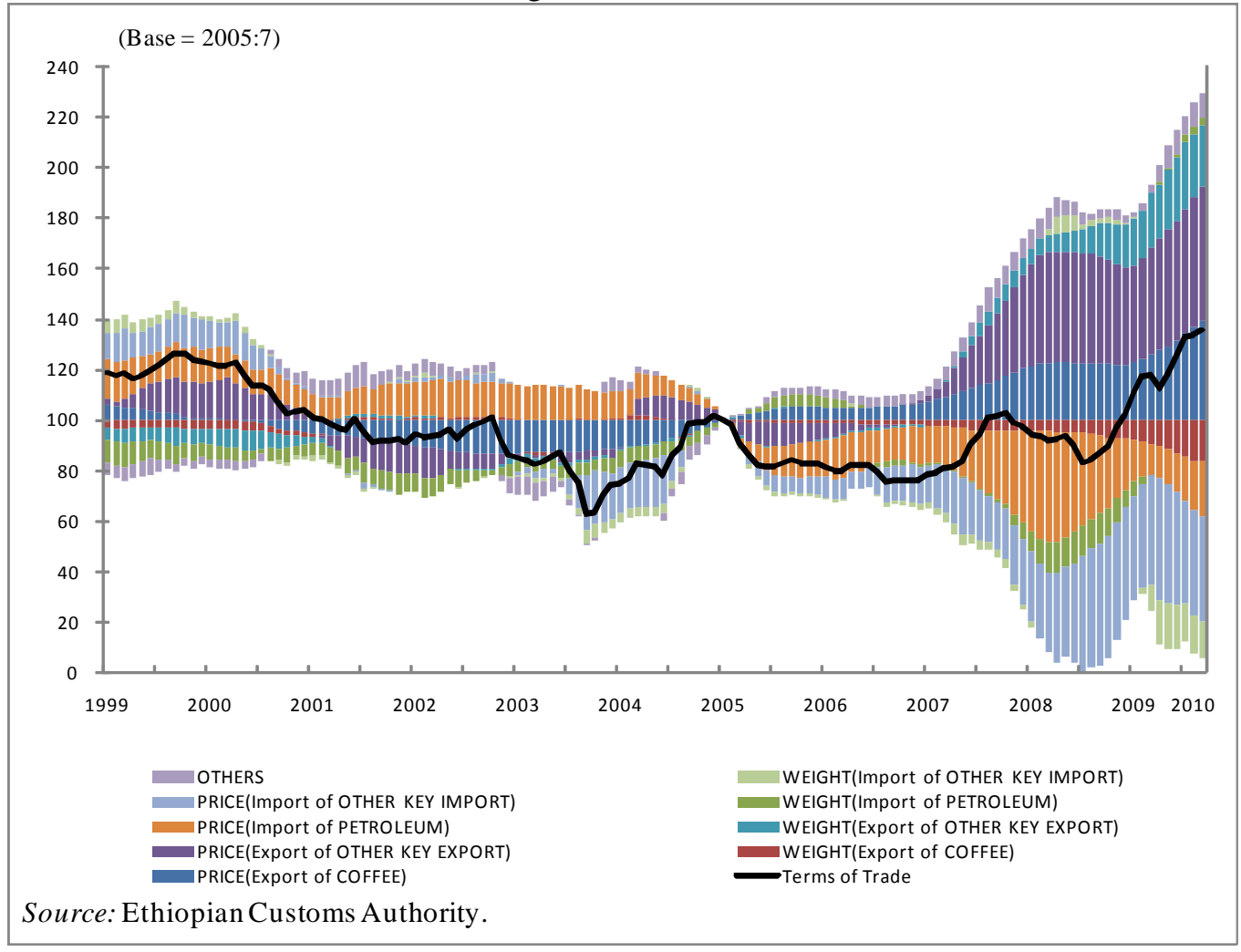


Figure 5. Ethiopia: Dynamics of Export Commodities, 2002-2008

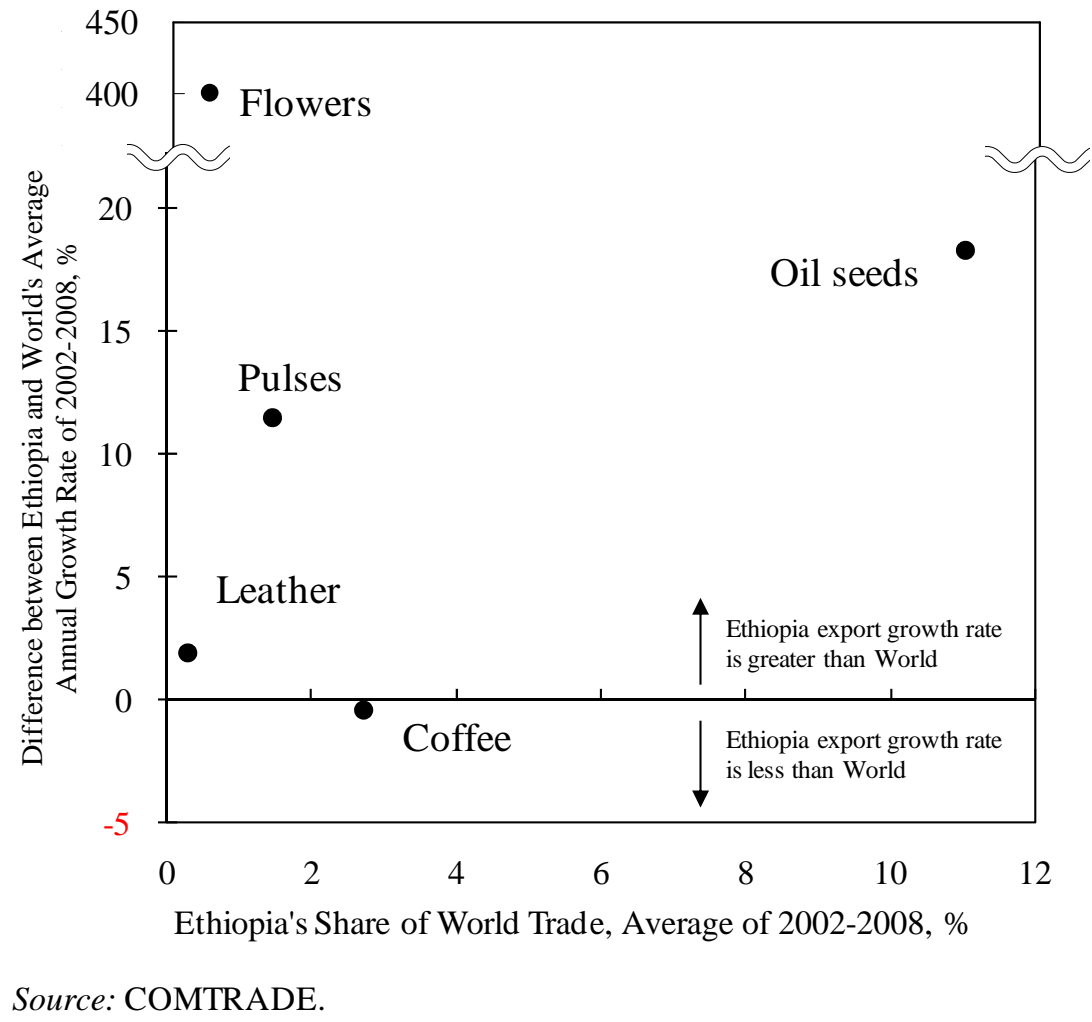

To confirm these findings with alternative data, Figure 5 plots Ethiopia's shares of key commodity exports in world trade, and the growth rate differences between Ethiopian exports and world exports. Coffee and leather exports from Ethiopia had about the same growth rate as world exports. On the other hand, oil seed, flower and pulse exports exceeded the growth rate of the world trade. Thus, Ethiopia expanded, in a relative sense, exports of selected commodities, except coffee.

\section{Conclusion}

We decompose its terms of trade fluctuations, especially during periods of the global food and financial crises. The results suggest that agricultural export diversification was instrumental in helping to keep the terms of trade stable, and eventually increase since mid-2008. 
Commodities will remain subject to future price fluctuations. To prevent risks from terms of trade volatility and shocks, continued export diversification can be beneficial. Diversification can be both horizontal, involving alternative economic activities, and vertical, involving the development of new products or marketing. For example, an estimated 95 percent of the Ethiopian coffee is organic, but is not labelled as such, and may suggest development potential.

In addition, Ethiopia needs to continue to improve domestic competitiveness, benefitting from policies and investments that support private and financial sector development in this area. Overall, the Ethiopian case underlines the benefits of export diversification. The applied methodology in this paper could be of interest to other countries.

We would like to thank Fátima Cardoso and Paulo Esteves for helpful comments, as well as Yuya Oshima for excellent research assistance. The views expressed in this paper are entirely those of the authors; they do not necessarily represent the views of the World Bank and its affiliated Organizations, or those of the Executive Directors of the World Bank or the governments they represent.

\section{References}

Baxter, M. and M.A. Kouparitas. 2006. "What Can Account for Fluctuations in the Terms of Trade?” International Finance (9)1: 63-86.

Blattman, C., J. Hwang, and J.G. Williamson. 2007. "Winners and losers in the commodity lottery: The impact of terms of trade growth and volatility in the Periphery 1870-1939.” Journal of Development Economics 82(1): 156- 179.

Cardoso, F. and P. Soares Esteves. 2008. "What Is Behind the Recent Evolution of Portuguese Terms of Trade?” Estudos e Documentos de Trabalho 5. Lisbon: Banco de Portugal.

Cashin, P., C.J. McDermott, and C. Pattillo. 2004. "Terms of trade shocks in Africa: are they short-lived or long-lived?” Journal of Development Economics 73(2): 727-744.

Jemma, D. and K. Zieschang. 2004. “Export and Import Price Indices.” IMF Staff Papers 51(1): 157-194.

Loening, J., D. Durevall and Y. Ayalew. 2009. "Inflation Dynamics in an Agricultural Economy: The Case of Ethiopia.” World Bank Policy Research Working Paper 4969.

Lloyd, P.J. and R.G. Procter. 1983. "Commodity Decomposition of Export-Import Instability: New Zealand.” Journal of Development Economics 12(1): 41-57. 